\title{
O APRISIONAMENTO DE INOCENTES NO CENTRO DE REEDUCAÇÃO FEMININO: UMA PERSPECTIVA CONCRETA DA GRAVIDEZ, DO NASCIMENTO E DA INFÂNCIA NO CÁRCERE FEMININO DE BELÉM-PA
}

\author{
Luana Miranda Hage Lins Leal Viegas ${ }^{1}$ \\ Oduvaldo Sérgio de Souza Seabra ${ }^{2}$
}

\section{RESUMO}

$\mathrm{O}$ presente artigo analisou aspectos que envolvem a gravidez de mulheres presas, o nascimento de seus filhos, o aprisionamento de crianças com sua genitora e a separação entre mãe e bebê no cárcere feminino da Região Metropolitana de Belém-PA. Para isso foi realizada pesquisa empírica, elaborada com enfoque no direito fundamental da presa ficar com seu filho durante o período de amamentação e nas disposições da Lei de Execuções Penais e das Regras de Bangkok sobre a maternidade no cárcere, averiguando a existência e eficácia de políticas públicas sobre o tema.

PALAVRAS-CHAVE: Gravidez e nascimento no cárcere; Maternidade na prisão; Políticas públicas; Centro de Reeducação Feminino - CRF.

\section{THE IMPRISONMENT OF INNOCENTS AT THE WOMEN'S REHABILITATION CENTER: A CONCRETE PERSPECTIVE OF PREGNANCY, BIRTH AND CHILDHOOD IN THE BELÉM-PA FEMALE PRISON}

\begin{abstract}
The present article analyzed aspects that involve the pregnancy of imprisoned women, the birth of their children, the imprisonment of children with their mother and the separation between mother and baby in the female prison of the Belém Metropolitan Region. To this end, an empirical research was conducted, focusing on the fundamental right of the prisoner to stay with her child during breastfeeding and on the provisions of the Criminal Execution Act and the Bangkok Rules on imprisonment, to ascertain the existence and effectiveness of public policies on the subject.
\end{abstract}

KEYWORDS: Pregnancy and birth in prison; Maternity in prison; Public policy; Female Rehabilitation Center - CRF.

\section{INTRODUÇÃO}

O presente artigo científico tem por objetivo conhecer e divulgar o dia a dia de mulheres presas e de seus bebês no interior do cárcere feminino da Região Metropolitana de Belém-PA. Inevitavelmente, percorrem-se diversas fases ou momentos, tais como: a gravidez,

\footnotetext{
${ }^{1}$ Mestranda em Direitos Fundamentais - PPGDF/UNAMA (PA). luana_hage@yahoo.com.br

${ }^{2}$ Mestrando em Direitos Fundamentais - PPGDF/UNAMA (PA). s.seabra@ icloud.com
} 
o parto, a amamentação, a breve convivência entre mãe e filho no ambiente prisional e, por fim, a separação.

No plano jurídico, analisam-se o direito assegurado na Constituição Federal (BRASIL, 1988) no inciso $\mathrm{L}$ do artigo $5^{\circ}$, que garante à presa o direito de ficar com seu filho no período da amamentação. Como desdobramento do direito fundamental citado, a Lei de Execuções Penais (BRASIL, 1984) dispõe que prisões femininas terão berçário - para as presas gestantes e aquelas com filhos até 6 meses de idade - e creche - às crianças maiores de 6 meses e menores de 7 anos. Por sua vez, as Regras das Nações unidas para o tratamento de mulheres presas e medidas não privativas de liberdade para mulheres infratoras, denominadas Regras de Bangkok, que consiste em um Tratado de Direitos Humanos do qual o Brasil é signatário, traz uma série de minúcias sobre o assunto. A luz dessas normas, visamos tecer discussões sobre a atuação do Estado para garantir a eficácia dos direitos previstos especificamente no Centro de Reeducação Feminino - CRF, único presídio feminino da região metropolitana de Belém-PA.

O presente estudo visa incentivar o leitor a uma reflexão, considerando os dados coletados na pesquisa empírica que alicerçam os argumentos qualitativamente trazidos à baila. Em síntese, busca-se refletir como se desenvolve a maternidade na prisão feminina de BelémPA.

\section{OBJETIVOS}

No presente artigo busca-se verificar se o CRF possui local adequado para abrigar presas gestantes e lactantes, se possui berçário para as crianças de até 6 meses de idade e se possui creche para crianças maiores de 6 meses e menores de 7 anos, como tais direitos são resguardados e como se dá o funcionamento do estabelecimento prisional com a finalidade de assegurar o direito à maternidade.

\section{METODOLOGIA}

\subsection{Os Métodos e as Técnicas de Pesquisa Utilizados}

A partir de uma abordagem empírica, buscou-se na pesquisa averiguar o cumprimento do direito fundamental das presas de ficarem com seus filhos no período de amamentação, se o CRF apresenta berçário e creche para os filhos das presas, quais as políticas públicas existentes com a finalidade de resguardar o direito à maternidade em ambiente carcerário e a 
possibilidade de fazer com que de alguma forma a sociedade se volte para o debate em questão.

Para tanto, utilizou-se a pesquisa qualitativa com o emprego dos seguintes métodos e técnicas: pesquisa bibliográfica (leitura de livros e revistas relacionados ao tema), pesquisa documental (leitura de leis, tratados de direitos humanos, conteúdos de sites, etc. sobre o assunto), pesquisa de campo (visita carcerária pelos pesquisadores, entrevista semidirigida com servidoras do estabelecimento prisional e com as presidiárias gestantes e com aquelas que deram a luz centro do cárcere) e relatos produzidos a partir da observação in loco do trabalho desenvolvido pelos pesquisadores.

\subsection{A Pesquisa Qualitativa}

A pesquisa qualitativa consiste na investigação científica de caráter subjetivo do objeto analisado, estudando as suas particularidades e experiências individuais. Significa dizer que o objetivo é identificar e analisar dados que não podem ser mensurados numericamente, com por exemplo, a observação e análise de sentimentos, intenções e comportamentos. Logo, os dados coletados não são tabulados para obtenção de resultados e sim para enfocar os pontos de vista dos entrevistados. Neste sentido, Igreja (2017, p. 14) leciona que

A pesquisa qualitativa se define por uma série de métodos e técnicas que podem ser empregados com o objetivo principal de proporcionar uma análise mais profunda de processos ou relações sociais. Seu uso não objetiva alcançar dados quantificáveis, ao contrário, objetiva promover uma maior quantidade de informações que permita ver o seu objeto de estudo em sua complexidade, em suas múltiplas características e relações.

Neste contexto, a presente pesquisa qualitativa visa compreender e interpretar o comportamento e expectativa de gestantes em privação de liberdade e, consequentemente, o nascimento de inocentes no cárcere, não para obter números como resultado, mas para retratar aspectos da realidade que possam nos indicar o caminho para tomada de decisão correta sobre a questão-problema, enquanto objeto deste artigo científico.

\subsection{A Pesquisa Bibliográfica}

A pesquisa bibliográfica visa responder o problema da pesquisa a partir da utilização de referenciais teóricos, fruto de estudos e análises, que, por conseguinte, passaram pelo crivo da ciência para serem apresentados para a sociedade (MAZUCATO, 2018, p. 66). Ressalta-se 
que a principal vantagem de tal pesquisa "reside no fato de permitir ao investigador a cobertura de uma gama de fenômenos muito mais ampla do que aquela que poderia pesquisar diretamente" (GIL, 2008, p. 50).

Dentro desta proposta, analisaram-se obras doutrinárias, artigos científicos publicados,

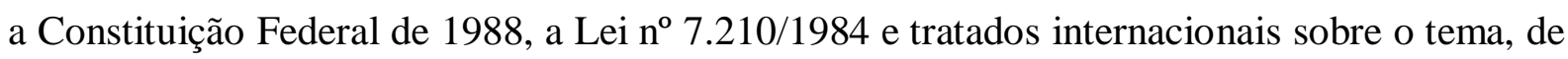
modo a construir um arcabouço teórico para alicerçar uma visão crítica acerca do que é expressão no ordenamento jurídico pátrio e a realidade concreta.

\subsection{A Pesquisa Documental}

A pesquisa documental assemelha-se muito à pesquisa bibliográfica. Diferenciam-se, todavia, quanto à natureza das fontes. Enquanto a pesquisa bibliográfica se utiliza fundamentalmente de fontes secundárias, ou seja, de trabalhos e estudos já realizados por outras pessoas, sendo acessados pelo pesquisador, mas cujo tratamento inicial não foi feito por ele. A pesquisa documental, por outro lado, utiliza fontes primárias, ou seja, documentos que registram fatos ou acontecimentos que não receberam qualquer tratamento analítico, seja porque os dados são obtidos de forma direta e feitos pelo próprio autor da pesquisa, seja também porque os documentos elaborados por terceiros podem ser analisados e reelaborados de forma direta pelo pesquisador de acordo com os objetivos da pesquisa (GIL, 2008, p. 51).

Neste contexto, a pesquisa documental teve por alicerce a análise de relatórios governamentais, conteúdos de sites e documentos relacionados ao tema que ainda não receberam tratamento científico. Deu-se relevo ao referencial teórico atual para melhor analisar, compreender e interpretar qualitativamente os dados da pesquisa.

\subsection{A Pesquisa de Campo}

A pesquisa de campo consiste em um estudo científico realizado no local de onde emergem os fatos e os fenômenos e visa extrair dados e informações diretamente da realidade através do uso de técnicas de coleta como entrevistas ou pesquisas para dar resposta a alguma situação ou problema abordado previamente (MAZUCATO, 2018, p. 66). Por conseguinte, foca-se em uma comunidade específica, sendo desenvolvida por meio da observação direta das atividades do grupo estudado (BASTOS, 2015, p. 83).

No caso em tela, o espaço ou fonte do qual decorrem as suas informações é o Centro de Reeducação Feminino, em Ananindeua-Pará, na região metropolitana de Belém. Assim, os 
pesquisadores realizaram visitas carcerárias e entrevistas semidirigidas com as presidiárias gestantes, com aquelas que deram à luz enquanto privadas de liberdade e com funcionárias do estabelecimento prisional.

A pesquisa de campo foi realizada em 21 e 22 de agosto de 2019 e se desenvolveu em três etapas. A primeira consistiu em um levantamento exploratório sobre o Centro de Reeducação Feminino - CRF e de informações relacionadas às condições das encarceradas. A segunda, consistiu na pesquisa empírica propriamente dita (entrevista com as presas e funcionárias). E, a terceira, consistiu na posterior análise dessas experiências.

\subsubsection{O Centro de Reeducação Feminino - CRF}

As penitenciárias femininas do Brasil surgiram na década de 1930 e eram oriundas de prédios construídos para encarcerar homens, logo, as estruturas prisionais femininas foram apenas adaptadas para recebê-las. Em alguns Estados da Federação, essa situação ainda é observada até os dias atuais em vários presídios femininos. Portanto, historicamente não há como dissociar a ideia de "cárcere feminino" e de "cárcere masculino", pois é perceptível que as raízes da estrutura social brasileira têm sido reproduzidas pelos mais diversos aspectos, inclusive o prisional.

No Brasil, a população carcerária feminina é de 42.355 mulheres distribuídas entre estabelecimentos penais femininos e mistos do sistema penitenciário. Contudo, o total de vagas disponibilizadas para mulheres é de apenas 27.029, ou seja, há um déficit global de 15.326 vagas, segundos os dados do Levantamento Nacional de Informações Penitenciárias INFOPEN Mulheres (BRASIL, 2017, p. 10-11).

No Estado do Pará, a população carcerária feminina em junho de 2019 era de 980 mulheres, sendo 267 custodiadas no interior do Estado e 713 na RMB - Região Metropolitana de Belém (SUSIPE, 2019, p. 4). Na RMB, há apenas uma casa penal feminina, o Centro de Reeducação Feminino está localizado no Município de Ananindeua, no Estado do Pará, fundado em 1977. A referida casa penal inaugurou a primeira Unidade Materno-Infantil do Norte do país, com um total de 14 leitos, destinada às detentas grávidas e às lactantes com filhos de até 6 meses de vida (SUSIPE, 2013).

\section{DESENVOLVIMENTO DA PESQUISA}

\subsection{A Gestação no Cárcere (Momento Pré-parto)}


A gravidez não é uma doença e sim uma condição que exige cuidados especiais para garantir uma gestação tranquila e, consequentemente, o bem-estar da mãe e do bebê. Desta forma, o estabelecimento prisional deve possuir não só acomodações e serviços médicos adequados para a gestante como também uma rotina institucional específica para tais situações, pois o estresse na gravidez causa distúrbios emocionais e psicológicos e esses sintomas são exacerbados pelo trauma do aprisionamento. De acordo com Bell. et al. (2004, p. 630, tradução nossa) "mulheres grávidas presas experimentaram sofrimento psicológico, complicações múltiplas e parto precário”. Assim, é crível afirmar que:

O embrião ou feto reage não só às condições físicas da mãe, aos seus movimentos psíquicos e emocionais, como também aos estímulos do ambiente externo que a afetam. O cuidado com o bem-estar emocional da mãe repercute no ser que ela está gestando. (SANTOS, et al. 2014. p. 19).

Neste contexto, é necessário considerar as distintas necessidades da gestante encarcerada, como por exemplo, cuidados com a saúde física e mental, acomodação prisional específica, individualização da pena, capacitação adequada de funcionários, flexibilização do regime prisional sempre que possível, entre outras.

No ordenamento supranacional, os direitos da gestante aprisionada são albergados pelas Regras de Bangkok: Regras das Nações Unidas para o Tratamento de Mulheres Presas e Medidas Não Privativas de Liberdade para Mulheres Infratoras, as quais dispõem sobre diretrizes e princípios sobre atendimento médico especializado, alimentação adequada, ambiente saudável, oportunidades regulares de exercícios físicos para gestantes, lactantes, bebês e crianças (BRASIL, 2016), bem como pelas Regras de Mandela: Regras Mínimas das Nações Unidas para o Tratamento de Presos, cuja finalidade não é descrever em detalhes um modelo de sistema prisional, mas sim oferecer balizas para a estruturação dos sistemas penais nos diferentes países, com base em princípios e regras de uma boa organização penitenciária e da prática relativa ao tratamento dos presos (BRASIL, 2016).

A Regra 6 de Bangkok assegura os cuidados com a presa grávida desde a sua entrada no cárcere ao estabelecer o exame médico de ingresso, o qual deverá incluir avaliação ampla para determinar a necessidade de cuidados de saúde básicos, o histórico de saúde reprodutiva da mulher presa, incluindo gravidez atual ou recente, partos e qualquer questão relacionada à saúde reprodutiva (BRASIL, 2016, p. 22).

\footnotetext{
3 “pregnant women experienced psychological distress, multiple complications, and poor birth outcomes".
} 
Ressalta-se que não se aplicarão sanções de isolamento ou segregação disciplinar a mulheres gestantes, conforme estabelece a Regra 22 de Bangkok (BRASIL, 2016, p. 25). A Regra 48 de Bangkok traz previsão expressa de direitos assegurados as mulheres gestantes presas ao estabelecer que estas deverão receber orientação sobre dieta e saúde dentro de um programa a ser elaborado e supervisionado por um profissional da saúde qualificado. A alimentação deverá ser gratuita, adequada e pontual, um ambiente saudável e oportunidades regulares de exercícios físicos para gestantes (BRASIL, 2016, p. 32).

A Regra 28 de Mandela estabelece que nas unidades prisionais femininas, deve haver acomodação especial para todas as necessidades de cuidado e tratamento pré e pós-natais (BRASIL, 2016, p. 24).

No ordenamento pátrio, a nível constitucional, o direito social da proteção à maternidade é assegurado no art. $6^{\circ}$ da Constituição Federal (BRASIL, 2019. p. 11). Especificamente, quanto aos direitos da reclusa grávida e do nascituro, a legislação infra constitucional dispõe sobre o cuidado cotidiano de modo a proteger os seguintes direitos e garantias fundamentais: direito à saúde, direito à alimentação, direito à acomodação adequada, assistência psicológica, entre outros, conforme dispõe os art. 14, § $3^{\text {o }}$ e art. 89, ambos da Lei de Execução Penal (BRASIL, 2019. p. 199 e 210-211) e art. $8^{\text {o }}$, $4^{\text {o }}$, do Estatuto da Criança e do Adolescente (BRASIL, 2018. p. 12).

\subsection{O Parto}

A gravidez e o parto são eventos sociais que integram a vivência reprodutiva de homens e mulheres. O parto, por conseguinte, marca o final de uma gravidez e o nascimento do bebê que deixa o útero da sua mãe. Este é um processo singular, uma experiência humana das mais significativas (BRASIL, 2001, p. 9).

A proteção ao parto da reclusa tem previsão em tratados e convenções internacionais, como por exemplo, a Regra 28 de Mandela que preconiza que devem-se adotar procedimentos específicos para que os nascimentos ocorram em um hospital fora da unidade prisional. Se a criança nascer na unidade prisional, este fato não deve constar de sua certidão de nascimento (BRASIL, 2016, p. 24).

Destaca-se ainda a Regra 24 de Bangkok que veda os instrumentos de contenção, como por exemplo o uso de algemas, em mulheres em trabalho de parto, durante o parto e no período imediatamente posterior (BRASIL, 2016, p. 25). Aliás, tal prática também é vedada 
pelo art. 292, parágrafo único, do Código de Processo Penal, o qual expressamente dispõe que "é vedado o uso de algemas em mulheres grávidas durante os atos médico-hospitalares preparatórios para a realização do parto e durante o trabalho de parto, bem como em mulheres durante o período de puerpério imediato" (BRASIL, 2019, p. 74).

\subsection{A Amamentação}

A amamentação ou aleitamento materno consiste em uma "estratégia natural de vínculo, afeto, proteção e nutrição para a criança e constitui a mais sensível, econômica e eficaz intervenção para redução da morbimortalidade infantil" (BRASIL, 2009, p. 9). "A amamentação, além de ser biologicamente determinada, é socioculturalmente condicionada, tratando-se, portanto, de um ato impregnado de ideologias e determinantes que resultam das condições concretas de vida" (ALMEIDA, 1999, p. 15).

$\mathrm{Na}$ amamentação, o bebê recebe anticorpos da mãe para a proteção de diversas doenças, além de auxiliar no crescimento e estabelecer uma maior relação afetiva entre mãe e filho. Logo, é um processo essencial para a saúde do bebê.

O direito à amamentação está previsto na Regra 48 de Bangkok que estabelece que as mulheres presas não deverão ser desestimuladas a amamentar seus filhos ou filhas, salvo se houver razões de saúde específicas para tal (BRASIL, 2016, p. 32).

O indigitado direito também é albergado no ordenamento jurídico pátrio. A nível constitucional, o art. $5^{\circ}$, L, da $\mathrm{CF} / 88$ dispõe expressamente que "às presidiárias serão asseguradas condições para que possam permanecer com seus filhos durante o período de amamentação" (BRASIL, 2016, p. 10). O Estatuto da Criança e do Adolescente, o qual é fundado no princípio do melhor interesse da criança, preconiza em seu art. $9^{\circ}$ que é dever do poder público propiciar condições adequadas ao aleitamento materno, inclusive aos filhos de mães submetidas a medida privativa de liberdade (BRASIL, 2018, p. 13). A Lei de Execução Penal também assegura tal direito no art. $83, \S 2^{\circ}$, na medida em que determina que os estabelecimentos penais destinados a mulheres serão dotados de berçário, onde as condenadas possam cuidar de seus filhos, inclusive amamentá-los, no mínimo, até 6 meses de idade (BRASIL, 2019, p. 209).

\subsection{Os Primeiros Meses de Convivência Entre Mãe e Filho no Ambiente}

\section{Intramuros}

Revista de Direito Penal, Processo Penal e Constituição | e-ISSN: 2526-0200 | Belém | v. 5 | n. 2 |

p. 47 - 66 | Jul/Dez. 2019. 
O vínculo afetivo entre mãe e filho começa antes de o bebê nascer. Após o nascimento, é fundamental que a mãe se mantenha próxima do filho para reforçar tal vínculo e desenvolver aspectos psíquicos saudáveis da personalidade da criança recém-nascida. Assim, os primeiros meses de convivência entre mãe e bebê estabelecerá relações de apego e se refletirá para toda a vida.

No ambiente intramuros, há cizânia doutrinária sobre a presença e permanência de bebês em estabelecimentos prisionais. Se, por um lado, os primeiros cuidados dados pela mãe são essenciais para a saúde física e mental do bebê, por outro lado, o ambiente prisional pode causar danos ao desenvolvimento do bebê.

Sob o aspecto biopsicossocial, privar o bebê de conviver com sua mãe pode contribuir não só para causar distúrbios psicológicos no binômio mãe-filho, como também afetar negativamente fatores biológicos e ainda deturpar fatores sociais como por exemplo: familiar, cultural, social, econômico, etc.

Sob o aspecto jurídico, preconiza o art. $8^{\circ}, \S 10$ do Estatuto da Criança e do Adolescente que é direito do bebê, cuja mãe se encontra sob custódia em unidade de privação de liberdade, ambiência que atenda às normas sanitárias e assistenciais do Sistema Único de Saúde para o seu acolhimento (BRASIL, 2018, p. 13). O art. 89 da Lei de Execuções Penais estabelece a obrigatoriedade da penitenciária de mulheres ser dotada de seção para gestante e parturiente e de creche para abrigar crianças maiores de 6 meses e menores de 7 anos, com a finalidade de assistir a criança desamparada cuja responsável estiver presa (BRASIL, 2019, p. 210-211).

Infelizmente a letra da lei não se concretiza na realidade, pois a criança no cárcere está sujeita a diversas formas de violência, como por exemplo, rebeliões, maus-tratos, influências iniciais na formação de personalidade, entre outros.

\subsection{A Separação}

A separação entre a mãe e o bebê é um dos maiores problemas enfrentados pelas mulheres encarceradas no sistema penitenciário feminino. Em regra, é dolorosa e gera sentimentos de perda e de impotência, pois a convivência entre mãe e bebê é rompida sem uma dinâmica de desligamento emocional. 
A Regra 52 de Bangkok estabelece que "a decisão do momento de separação da mãe de seu filho deverá ser feita caso a caso e fundada no melhor interesse da criança, no âmbito da legislação nacional pertinente" (BRASIL, 2016, p. 33).

No Brasil, o art. 83, $\S 2^{\circ}$ da Lei de Execução Penal assegura o direito da encarcerada permanecer com seu filho até 6 meses (BRASIL, 2019, p. 209). Após tal lapso temporal, o contato entre mãe e filho(a) só ocorre por meio de visitas periódicas promovidas pelo responsável ou, nas hipóteses de acolhimento institucional, pela entidade responsável, independentemente de autorização judicial, conforme preconiza o art. 19, § $4^{\circ}$ do Estatuto da Criança e do Adolescente (BRASIL, 2018, p. 18).

\subsection{Políticas Públicas}

As políticas públicas são prestações estatais que visam efetivar os direitos fundamentais de $2^{a}$ dimensão, os quais se relacionam com a "igualdade", baseado no princípio da dignidade humana, destinadas às pessoas em situação de maior vulnerabilidade (COELHO, 2017).

A principal política pública é o desenvolvimento nacional, que deve estar em consonância com todas as demais, vez que tem como finalidade de melhoria das condições sociais da população (BERCOVICI, 2006).

O Estado é o principal promotor de desenvolvimento e para isso:

[...] deve ter autonomia frente aos grupos sociais, ampliar suas funções e readequar seus órgãos e estrutura. $O$ papel estatal de coordenação dá a consciência da dimensão política da superação do subdesenvolvimento, dimensão esta explicitada pelos objetivos nacionais e prioridades sociais enfatizados pelo próprio Estado. As reformas estruturais são o aspecto essencial da política econômica dos países subdesenvolvidos, condição prévia e necessária da política de desenvolvimento. Coordenando as decisões pelo planejamento, o Estado deve atuar de forma muito ampla e intensa para modificar as estruturas socioeconômicas, bem como distribuir e descentralizar a renda, integrando, social e politicamente, a totalidade da população. (BERCOVICI, 2006, p. 158).

O alcance do desenvolvimento se dá mediante plano e planejamento. Plano distinguese de planejamento, ao passo que este cuida-se de um processo político, que exige um Estado forte e confere uma finalidade à atuação do mesmo no cumprimento dos objetivos delimitados no artigo $3^{\circ}$ da CF. Não é neutro, vez que consiste numa escolha entre possibilidades diversas, eleita por questões políticas e ideológicas; enquanto aquele "é a expressão da política geral do 
Estado" (BERCOVICI, 2006, p. 145), devendo estar em consonância ideologia constitucional, é a concretização.

Bercovici aponta ainda dificuldades em adequar os fins da política de desenvolvimento estatal à administração pública, vez que a administração pública está alinhada ao modelo liberal de proteção dos direitos individuais em face do Estado, dotada de tradicionalismo, modificações improvisadas insuficientes a promoção do desenvolvimento.

O Estado brasileiro apresenta dificuldades em formular e executar uma política de desenvolvimento continuada, vez que necessita do alinhamento entre os órgãos executores, o planejamento (processo) e o plano (concretização).

Na década de 70 houve a tentativa de implementação de um estado neoliberal, que substituísse o Estado intervencionista pelo regulador, que acarretou um sucateamento do Poder Público. Desta forma, necessário se faz um fortalecimento do Estado e reorganização da administração pública, a fim de promover os objetivos constitucionais por intermédio de políticas públicas.

Entretanto,

[...] não há dúvidas de que, ao menos naquilo que se refere ao cumprimento do "mínimo vital", resta inequívoca a inadmissibilidade de o Estado furtar-se à concretização de um dado direito fundamental social, sob pena de esvaziamento de seu conteúdo e de desrespeito ao princípio da dignidade da pessoa humana. (COELHO, 2017, p. 94).

Os direitos sociais são também chamados de direitos-meio, vez que oportunizam a materialização dos direitos de $1^{\text {a }}$ dimensão, direitos relacionados a liberdade e que exigem uma abstenção do Estado. $\mathrm{O}$ arrolamento de uma série de direitos sociais elevados à categoria de direitos fundamentais fortalece a ideia de Estado Social e Democrático de Direito, com duas funções:

[...] a primeira, de cunho instrumental, viabiliza outros direitos fundamentais, e a segunda, de cunho material, permite a emancipação do indivíduo, com respeito da sua dignidade humana, por meio de prestações positivas do Estado. (COELHO, 2017, p. 97.)

Entretanto, políticas públicas para pessoas presas geralmente não são bem vistas pela maioria da sociedade brasileira, dando a ideia de superproteger injustificadamente quem cometeu um crime e que deve pagar e sofrer por isso. Nesta esteira, Alves afirma que o cárcere se afastou das justificativas punitivas e se transformou em uma ferramenta viável ao 
Estado, devido consistir em uma política econômica imediatista num cenário de ausência de planejamento (2019). Em seguida complementou:

Tudo ocorreria como uma forma de dar uma destinação para uma parcela economicamente certa da sociedade, gerar demanda, criar novos postos de trabalho e manter uma lógica consensual capitalista de controle e coisificação de pessoas. (ALVES, 2019, p. 15).

Ademais, o encarceramento das classes marginalizadas finda por alimentar um outro sistema de trabalho, ignorando os direitos dos presos, os quais já estão silenciados pela pobreza, exclusão e preconceito:

Ao superlotar o cárcere, as demandas em saúde, educação e assistência
social diminuem. Se o público que demanda tal estrutura reduz, os
investimentos nessa seara seguem o mesmo fluxo.
A demanda gerada pela superlotação do cárcere gera a necessidade de
criação de novas instituições desse porte e de estruturação das agências
estatais conectadas ao devido processo legal. Tal gasto estatal é direcionado
a produção e manutenção de (novos) postos de trabalho. Destaca-se que tais
postos não se dão para todos, mas somente para aqueles que possuem
condições estabelecidas nos editais dos certames licitatórios e concursais.
Por esta lógica, se neutraliza de forma seletiva aqueles que o sistema social
não consegue (ou não quer) incluir. Tal lógica se dá em conjunto com uma
estrutura penal que busca objetivos de eficiência massificados, aplicando a
norma de forma rígida (baseado em uma racionalidade sistêmica e formal),
baseado em padrões penais capitalistas e voltados a legitimar tal fim,
implementando técnicas de controle sobre determinados grupos sociais. A
gestão administrativa da penalidade responde a uma lógica interna
completamente desconectada com a maioria dos preceitos e garantias
individuais. (ALVES, 2019, p. 22).

Assim, percebemos dois impasses: um do ponto organizacional do Estado brasileiro, que apresenta falhas em diversos segmentos que assegurem a realização de direitos, e outro de políticas públicas para pessoas encarceradas serem geralmente impopulares. Todavia, apenas através de políticas públicas é possível a materialização dos direitos ora em análise.

\subsection{A Inserção no Campo}

Em regra, a entrada do pesquisador na prisão para realizar uma pesquisa é bastante difícil e está sujeita às intempéries sociais e às conjunturas políticas. Logo, a inserção do pesquisador no cárcere é sempre precária e provisória (BRAGA, 2014, p. 53). A primeira dificuldade, normalmente, refere-se à autorização do Secretário Extraordinário de Assuntos Penitenciários para realizar tal atividade. Superada tal fase, realizou-se o primeiro contato com funcionárias e com as encarceradas. Ressalta-se que a entrada no cárcere de pessoas 
estranhas à sua dinâmica é vista como uma ameaça ao controle e à segurança (BRAGA, 2014, p. 53). Por outro lado, possuir um histórico de trabalho em prisões encurtou caminhos, viabilizou o acesso ao "locus" e aproximou pesquisadores e voluntárias. Na verdade, são várias as dificuldades que o pesquisador tem que superar para realizar uma pesquisa em um ambiente hermeticamente fechado como a prisão.

\subsection{As Entrevistas com as Presas e Funcionárias}

As entrevistas foram realizadas nos dias 21 e 22 de agosto de 2019 no período da tarde. Antes de iniciar a entrevista, explicou-se o objetivo do estudo e a importância da participação da pessoa entrevistada. A concordância de cada participante se materializou com a assinatura de um termo de consentimento livre e autorização do uso das informações na indigitada pesquisa.

Adotou-se a entrevista semiestruturada ou semidiretiva, que, embora seja estruturada e dirigida pelo pesquisador, permite que os entrevistados falarem o que julgarem importante a partir de suas percepções sobre determinado aspecto da realidade social (XAVIER, 2017, p. 125).

No dia 21 de agosto de 2019, a visita ao Centro de Reeducação Feminino (CRF) foi curta, devido procedimento de revista que estava ocorrendo no estabelecimento, foi possível apenas entrevistar uma servidora, a qual informou que o CRF conta com uma Unidade Materno-Infantil (UMI), com capacidade para 14 detentas, entre presas provisórias e condenadas, que abriga grávidas e mulheres com filhos até 6 meses de idade, não possui berçário (para crianças entre 6 meses a 2 anos) e nem creche (para crianças entre 2 a 7 anos). A servidora informou que quando uma mulher ingressa no sistema prisional, é submetida a exames, dentre eles um que detecta gravidez, que, caso confirmada, faz com que a detenta seja transferida de imediato para a UMI. Ao final, a funcionária mostrou uma cozinha em que são produzidas refeições às presas e uma obra de onde está sendo construída uma nova Unidade Materno Infantil.

No dia subsequente, 22, houve retorno ao campo, sendo permitido realizar entrevista com 2 servidoras da UMI e com mulheres lá presas. A UMI funciona em uma casa ampla, separada do CRF, a uma distância aproximadamente 1 quilômetro deste, com áreas externas laterais e ao fundo. No espaço interno, possui dois quartos grandes (um para gestantes e outro para lactantes), ambos com banheiro e munidos com camas, poltronas, televisão, armários, ar 
condicionado, ventiladores e materiais pessoais. Também há uma enfermaria com banheiro (com local para coleta do exame de colo de útero, remédios, balança, ar condicionado, aparelho de nebulização, mesa e duas cadeiras para atendimento médico), uma cozinha (com 2 pias, fogão, panelas, filtro de água, liquidificador, geladeira e forno de microondas), um refeitório (com mesa e bancos), uma brinquedoteca (com livros, brinquedos, mesa e cadeiras infantis) e uma secretaria. Ao longo da UMI é perceptível muitas infiltrações e mofo nas paredes.

Na UMI há atendimento médico semanal às grávidas, lactantes e filhos, há técnica de enfermagem, enfermeira, psicóloga, assistente social e nutricionista. Os exames de ultrassonografia são realizados pelo Sistema Único de Saúde - SUS (fora da UMI), agendados pelo setor de saúde do CRF. Os partos ocorrem, em geral, na Santa Casa de Misericórdia de Belém-PA. As presas permanecem com seus filhos até os seis meses de vida, quando são encaminhados à família ou para um abrigo, já a mãe, é transferida para o CRF.

No que concerne a alimentação na UMI, a SUSIPE conta com uma nutricionista, a qual organiza previamente o cardápio daquela unidade e supervisiona a comida repassada às presas. As internas da UMI recebem diariamente 6 refeições: café da manhã, lanche, almoço, lanche, jantar e ceia. O café da manhã é composto de café com leite (preparado na UMI pelas presas) e pão com manteiga. $\mathrm{O}$ almoço e a janta são preparados numa cozinha existente no CRF, administrada pela Comércio e Indústria de Alimentos LTDA - CIAL -, composto de arroz, salada, uma proteína animal (carne, frango ou peixe) e feijão (num pote a parte). No lanche da manhã é servido suco de fruta (preparado na UMI) com bolacha, no da tarde recebem uma fruta cada (maçã, pera, mamão, banana ou tangerina). Na ceia recebem mingau ou sopa ou chocolate quente com pão. A água para beber é de acesso livre a todas as presas, mediante um filtro na cozinha.

A amamentação das crianças é estimulada na UMI, exceto se a mãe for portadora do vírus HIV ou se a criança apresentar intolerância à lactose. Quando o bebê completa 5 meses de nascido, a amamentação é mantida, porém a nutricionista da SUSIPE insere na alimentação dele papinha doce (feita com frutas) e papinha salgada (com legumes e uma proteína animal - frango ou carne bovina), devido a possível separação entre mãe e bebê.

Em relação a entrevista com as presas, foi questionado acerca da idade, cor, estado civil, crime, comarca onde responde ou respondeu processo, grau de instrução, a renda, se 
recebe visita, se gestante, lactante ou mãe de criança não lactente. Após, foram feitas as perguntas:

1. O Centro de Reeducação Feminino tem estrutura hospitalar/maternal adequada para a gestante e lactantes?

2. O Centro de Reeducação Feminino possui Unidade Materno-infantil, Berçário e Creche?

3. O Presídio disponibiliza assistência médica, odontológica e psicológica (mãe /filhos)?

4. Você recebeu atendimento médico durante o pré-natal e o pós-parto no presídio?

5. É fornecida assistência material, como kit maternidade, remédio, roupas, mamadeiras, banheira, materiais de higiene, berço, chupeta, etc.?

6. Tem/Teve alguma complicação durante a gestação, parto ou pós-parto?

7. Você amamentou/amamenta o seu bebê?

8. Quantos tempo (meses) o bebê permaneceu com você?

9. A alimentação é diferenciada para a gestante, lactante e para o bebê?

10. A acomodação é diferenciada para a gestante, lactante e para o bebê?

11. Com quem ficará o bebê após a separação?

12. Como se dá a separação entre mãe e bebê? Você está recebendo algum acompanhamento? (idade da criança, preparação psicológica, melhor interesse da criança, para onde a mãe vai, etc).

Das 14 presas que ali se encontravam, apenas 8 aceitaram ser entrevistadas. Da pesquisa se verificou:

A - Quanto a idade das entrevistadas: 2 tinham entre 18 a 24 anos; 4 tinham de 25 a 29 anos; 2 tinham entre 30 a 34 anos; e não foi registrada nenhuma acima de 35 anos de idade;

B - Quanto a acusação penal: 6 estavam presas pelo crime de tráfico de drogas; 1 pelo crime de roubo; e uma por tráfico e roubo;

C - Quanto a cor: 5 eram negras; 1 parda; e 2 brancas;

D - Quanto a comarca processante: 5 estavam presas por comarcas do interior e 3 pela região metropolitana de Belém;

E - Quanto ao Grau de escolaridade: 1 era analfabeta; 3 com ensino fundamental incompleto;

2 com ensino médio incompleto; 2 com ensino médio completo;

F - Quanto as Visitas: 2 não recebem visitas e 6 recebem de amigos e familiares;

G - Situação: 4 lactantes e 4 gestantes; 
H - 4 consideram a UMI adequada para grávidas, lactantes e bebês; 3 consideram parcialmente adequada, informando que gostariam de ter mais atenção do Estado no sentido de não ter dificuldade na saída da UMI para a realização de exames externos e de ter mais atendimento psicológico e com assistente social; 1 considerou a UMI ruim, reclamando a falta de conforto;

I - Saúde: 7 receberam atendimento médico; 1, que estava presa há uma semana, disse não ter recebido atendimento até então;

J - Assistência material: As presas relataram que receberam da SUSIPE medicamentos, fraldas descartáveis, lençóis, sabonete para elas e absorventes (quando lactantes). Demais itens para os bebês como roupas, banheira e material de higiene receberam através de doações.

K - Quanto a complicações: 4 não tiveram complicações na gravidez ou parto; 1 possui anemia; 1 apresentou DST na gestação; 1 teve parto prematuro; e 1 reclamou da demora de 6 horas de viatura para levá-la ao hospital quando entrou em trabalho de parto.

L - Quanto a Amamentação: as 4 mulheres entrevistadas que já tinham tido o filho, amamentam;

M - Desligamento: 1 mulher já estava em atendimento com o Setor Social do CRF iniciando o procedimento de separação entre mãe e bebê;

$\mathrm{N}$ - Alimentação: 1 mulher não reclamou da comida oferecida; 7 reclamaram da comida, afirmando que alimentos como arroz, feijão e a carne oferecida nem sempre estão devidamente cozidos ou estão com pouco sal.

O - Acomodações: 6 qualificaram como boa as acomodações da UMI; 1 qualificou como razoável, reclamando que o ar condicionado não estava funcionando e tinha muito mosquito; 1 qualificou a UMI como ruim;

$\mathrm{P}$ - Todas mencionaram não realizarem atividades físicas, de lazer ou estudo;

Q - Questionadas com quem ficariam os bebês em caso de separação: 1 informou que não tem com quem deixar; 1 encaminharia aos seus avós maternos; 1 deixaria com uma amiga; 5 deixariam com seus pais ou irmãos. Porém, todas demonstraram esperança em sair da UMI junto com seus filhos, especialmente as que tem outros filhos pequenos.

As presas entrevistadas demonstraram muita angústia ao questionamento da separação do bebê, principalmente em caso de encaminhamento para abrigo público. 
Da entrevista com os servidores foi relatado que a separação entre mãe e bebê ocorre da seguinte forma: o setor social conversa com a interna, verifica pelo histórico familiar e afetivo se teria alguém apto a receber e ser o guardião da criança. Os familiares são avaliados pelos servidores do CRF. São acionados o Conselho Tutelar e as equipes técnica e administrativa do CRF para o momento da separação. A criança é entregue ao novo guardião e a mãe é encaminhada à prisão comum novamente.

A unanimidade, as servidoras entrevistadas disseram que a separação entre mãe e bebê é um momento terrível, de muito sofrimento, o qual elas não gostam de testemunhar. Informaram também não ter conhecimento de políticas públicas para implantação de creches no CRF para crianças de até 7 anos de idade.

No caso em tela, buscou-se compreender os comportamentos, as experiências, as rotinas, as expectativas, entre outros fatores compartilhados pelas encarceradas cujos filhos nasceram no CRF.

\section{CONSIDERAÇÕES FINAIS}

Depreende-se da pesquisa realizada que os direitos de mulheres presas, relacionados a maternidade, estão sendo parcialmente assegurados no CRF. Explicamos: com a fundação da UMI do CRF foi permitido a presas grávidas, lactantes e seus filhos uma acomodação melhor do que a existente no ambiente propriamente prisional, sendo também assegurado o direito das detentas de ficarem com seus filhos por um período mínimo de 6 meses após o nascimento e de terem acesso a atendimento médico regular. As presas e filhos recebem, seja da SUSIPE ou por doações, materiais de higiene, roupas, lençóis e alimentação diferenciada, determinada por uma nutricionista.

Por outro lado, o CRF não possui creche e nenhum servidor soube informar se há previsão para implantação, embora o texto legal que trouxe tal previsão já tenha cerca de 10 anos. A comida oferecida às presas deve ser fiscalizada com mais rigor, vez que as encarceradas reclamaram da qualidade do cozimento e do gosto. É necessário realizar uma reforma na UMI para que sejam retiradas as infiltrações e o mofo. As presas também devem realizar alguma atividade educativa e de lazer, pois ficam restritas aos cuidados com o bebê e assistir TV. Por fim, a separação entre mãe e bebê deve atentar ao melhor interesse da criança e não a uma idade específica. 


\section{REFERÊNCIAS}

ALMEIDA, João Aprigio Guerra de. Amamentação: um híbrido natureza-cultura. Rio de Janeiro: Editora Fiocruz, 1999.

BASTOS, Maria Clotilde Pires. Metodologia Científica. Londrina: Editora e Distribuidora Educacional S.A., 2015.

BELL, Janice F. et al. Jail Incarceration and Birth Outcomes. Journal of Urban Health: Bulletin of the New York Academy of Medicine, New York, vol. 81, n. 4, p. 630-644, 2004. Disponível em: <https://doi.org/10.1093/jurban/jth146>. Acesso em: 02 ago. 2019.

BERCOVICI, Gilberto. Planejamento e políticas públicas: por uma nova compreensão do papel do Estado. In BUCCI, Maria Paula Dallari (Org.). Políticas Públicas: Reflexões sobre o conceito Jurídico. São Paulo, Saraiva, 2006.

BRAGA, Ana Gabriela Mendes. Criminologia e Prisão: caminhos e desafios da pesquisa empírica no campo prisional. In: Revista de Estudos Empíricos em Direito - Brazilian Journal of Empirical Legal Studies. São Paulo, vol. 1, n. 1, p. 46-62, jan. 2014.

BRASIL. Conselho Nacional de Justiça. Regras de Bangkok: Regras das Nações Unidas para o Tratamento de Mulheres Presas e Medidas Não Privativas de Liberdade para Mulheres Infratoras. 1. ed. Brasília: Conselho Nacional de Justiça, 2016.

BRASIL. Conselho Nacional de Justiça. Regras de Mandela: Regras Mínimas das Nações Unidas para o Tratamento de Presos. 1. ed. Brasília: Conselho Nacional de Justiça, 2016.

BRASIL. Constituição (1988). Constituição da República Federativa do Brasil. Brasília: Senado Federal, 2019.

BRASIL. Estatuto da Criança e do Adolescente. 2. ed. Brasília: Senado Federal, 2018. 
BRASIL. Lei $n^{\circ}$. 7.210, de 11 de julho de 1984. Institui a Lei de Execução Penal. In: Coletânea Básica Penal. 9. ed. Brasília: Senado Federal, 2019.

BRASIL. Ministério da Justiça. Levantamento Nacional de Informações Penitenciárias INFOPEN Mulheres. 2. ed. Brasília: Departamento Penitenciário Nacional, 2017.

BRASIL. Ministério da Saúde. Parto, aborto e puerpério: assistência humanizada à mulher. Brasília: Ministério da Saúde, 2001.

BRASIL. Ministério da Saúde. Saúde da criança: nutrição infantil: aleitamento materno e alimentação complementar. Brasília: Ministério da Saúde, 2009.

COELHO, Rodrigo Batista. Direitos Fundamentais Sociais e Políticas Públicas: subjetivação, justiciabilidade e tutela coletiva do direito à educação. Leme: Habermann Editora, 2017.

FONTANA, Felipe. Técnicas de Pesquisa. In: MAZUCATO, Thiago (Org.). Metodologia da Pesquisa e do Trabalho Científico. Penápolis: Funepe, 2018. p. 59-78.

GIL, Antônio Carlos. Métodos e Técnicas de Pesquisa Social. 6. ed. São Paulo: Atlas, 2008.

IGREJA, Rebecca Lemos. O Direito como objeto de estudo empírico: o uso de métodos qualitativos no âmbito da pesquisa empírica em Direito. In: MACHADO, Maria Rocha (Org.). Pesquisar Empiricamente o Direito. São Paulo: Rede de Estudos Empíricos em Direito, 2017. p. 11-38.

MAZUCATO, Thiago. Métodos. In: MAZUCATO, Thiago (Org.). Metodologia da Pesquisa e do Trabalho Científico. Penápolis: Funepe, 2018. p. 54-58.

RIESEMBERG, Adriana Ossovski. Mulheres, tráfico de drogas e violência de gênero. In ARGÜELlO, Katie Silene Cáceres; SÁ, Priscilla Placha (Coordenadoras). ROMFELD, 
Victor Sugamosto; SIMÕES, Heloisa Vieira (Organizadores). Criminologias: feminismos, mídia e protestos sociais. Curitiba: Editora Virtual Gratuita - EVG, 2018.

SANTOS, Marcos Davi dos. et al. Formação em pré-natal, puerpério e amamentação: práticas ampliadas. São Paulo: Fundação Maria Cecilia Souto Vidigal, 2014. (Coleção Primeiríssima Infância, v. 3).

SUPERINTENDÊNCIA DO SISTEMA PENITENCIÁRIO DO PARÁ. SUSIPE em Números. Belém, 2019. Relatório.

SUPERINTENDÊNCIA DO SISTEMA PENITENCIÁRIO DO PARÁ (SUSIPE). Centro de Reeducação Feminino - CRF. Belém, 2013. Disponível em: < http://www.susipe.pa.gov.br/unidade-prisional/metropolitana/ananindeua/centro-dereeducação-feminino---crf>. Acesso em 5. ago. 2019.

XAVIER, José Roberto Franco. Algumas notas sobre a entrevista qualitativa de pesquisa. In: MACHADO, Maria Rocha (Org.). Pesquisar Empiricamente o Direito. São Paulo: Rede de Estudos Empíricos em Direito, 2017. p. 119-160. 